\title{
Relationships among Psychosocial Correlates and Stages of Change in a German-Chinese Sample
}

\author{
Helmut Strobl1, Yanping Duan², Susanne Tittlbach1, Walter Brehm \\ ${ }^{1}$ Institut of Sport Science, University Bayreuth, Bayreuth, Germany \\ ${ }^{2}$ Hong Kong Baptist University, Hong Kong, China \\ Email: helmut.strobl@uni-bayreuth.de
}

Received 25 November 2015; accepted 26 February 2016; published 29 February 2016

Copyright (C) 2016 by authors and Scientific Research Publishing Inc.

This work is licensed under the Creative Commons Attribution International License (CC BY).

http://creativecommons.org/licenses/by/4.0/

(c) (i) Open Access

\begin{abstract}
Promoting Health Enhancing Physical Activity (HEPA) behavior is an important undertaking in Germany as well as in China. In order to create successful interventions in different nations, knowledge about the relevant psychosocial correlates that may encourage successful progression through the behavior change process is necessary. Therefore, the relationships of selected psychosocial correlates of physical activity with stages of change were examined in a German-Chinese sample. In total, 2071 adults (865 Germans, 1206 Chinese) completed a questionnaire. The theoretical frame-work used was the FIT-model, which consists of the following stages of change: not considering, considering, preparing, exploring, fluctuating and maintaining. All data were analyzed with a two-way ANOVA. Significant main effects for the stages of change on all psychosocial correlates were found. Significant interactions between stages and nations emerged for all correlates except for social support, although these results revealed small effect sizes. To progress within the stages of inactivity, interventions should focus on outcome expectations, barriers, social support and affective attitudes. The successful initiation of physical activity depends on considerations of barriers, maintenance self-efficacy, intrinsic motivation and affective attitudes. These same correlates plus social support are relevant for long-term adherence to physical activity. In Germany, perceived barriers and emotional aspects of physical activity appear to be important for initiating and maintaining regular physical activity. Furthermore, for long-term adherence to physical activity, Germans - in contrast to Chinese adults-may not necessarily benefit from social support; however they could benefit from learning how to strengthen their physical activity outcome expectations.
\end{abstract}

\section{Keywords}

Health Enhancing Physical Activity, Stage Model, Psychosocial Correlates, China, Germany 


\section{Health Enhancing Physical Activity (HEPA) Promotion}

The physical and mental health benefits of regular participation in physical activity are well documented [1]. According to the World Health Organization (WHO) recommendations for HEPA [2], it is suggested that adults should enhance their fitness (especially aerobic capacity, muscle strength, coordination) by engaging in at least 150 minutes per week of moderate intensity physical activity and exercise (corresponding to a consumption of about $800 \mathrm{kcal} / \mathrm{wk}$ ). In Germany, 37.4\% of men and 32.7\% of women claim to be sufficiently physical active; however, only $25.4 \%$ of men and $15.5 \%$ of women reach the HEPA level recommended by WHO [3]. The participation rate in China appears to be even lower, with only $11.9 \%$ of Chinese adults reporting leisure-time physical activity of moderate or vigorous intensity for at least 10 minutes, three times per week [4]. This situation has become a public health concern and there is an urgent need to increase physical activity levels in both German and Chinese populations; however, inducing behavior change from sedentary to active behavior is a long and complex process. The mechanisms of this process are described in various stage models such as the Transtheoretical Model (TTM) [5], the Health Action Process Approach (HAPA) [6] or the FIT-Model [7]. Stage models describe behavior change as a dynamic process that involves movement through a sequence of discrete, qualitatively distinct stages. Additionally, a broad array of psychosocial factors is associated with physical activity behavior change over time. As such, people at various stages are likely to require interventions specifically designed for each stage of behavior change to encourage or support their progression to the subsequent stage in the sequence. Appropriate knowledge of the mechanisms described by stage models can be used to develop appropriate systematic interventions to increase levels of physical activity-and thereby health promotion [8] [9].

\section{Health Enhancing Physical Activity Integrated into a Behavior Stage Model}

The "Four Steps from Inactivity to Activity Model” (FIT-Model) [7] was specifically developed as a theoretical framework to study HEPA. This model is based on the main stages of the TTM, and is supplemented with a further "fluctuation" stage [10]. The criteria for physical activity duration for the stages of change are guided by the WHO-recommendations for HEPA. The stages are defined as:

Not considering: Performing less than an accumulated 150 minutes of physical activity per week and not thinking about performing any more activity.

Considering: Performing less than an accumulated 150 minutes of physical activity per week, but thinking about performing more activity.

Preparing: Performing less than an accumulated 150 minutes of physical activity per week as well as intending to and having concrete plans to perform more activity.

Exploring: Performing physical activity for at least an accumulated 150 minutes per week, for a period of less than 12 months.

Fluctuating: Performing physical activity for at least an accumulated 150 minutes per week, but not regularly i.e. not every week.

Maintaining: Performing physical activity for at least an accumulated 150 minutes per week, for a period of 12 months or longer.

The time requirement of twelve months for the "exploring" stage is doubled compared to the "action stage" of TTM. The rationale for this was based on research assessing the dropout and adherence rate of HEPA [11]. Furthermore, the FIT-Model posits that there are sequential and logical relationships among the stages of change for PA, psychosocial correlates and health outcomes. Therefore, by improving critical psychosocial correlates through intervention, there is potential to encourage inactive to active stage progression, which can subsequently lead to positive health consequences.

Six psychosocial correlates were integrated into the FIT-Model: maintenance self-efficacy, outcome expectation, perceived barriers, social support, affective attitude and intrinsic motivation. The selection of these correlates was based on two selection criteria: 1) Strong relationships have been shown with physical activity in separate reviews over recent years [12] [13]; 2) Intervention studies have successfully increased PA behavior by addressing the selected correlates [14].

Existing knowledge about the importance of selected correlates in promoting physical activity behavior and their association with the stages of change is summarized below. 
Outcome expectations (expected benefits of physical activity in the long- or short-term) reflect reasons for engaging in physical activity [15]. According to various surveys, expected health benefits are among the main reasons to be physically active [16]. The importance of outcome expectations to form an intention to be physically active has already been supported by research using the theoretical framework of the Theory of Planned Behavior [17]. However, outcome expectations have minimal influence on the maintenance of physical activity behavior [14].

Perceived Barriers (subjective reasons that prevent people from performing physical activity) play a major role in changing behavior [18]. Studies show that-however well-intentioned-many people still fail to initiate physical activity behavior when they face too many barriers ("intention-behavior gap”) [19]. Particularly, having no time, lack of motivation/willpower and-especially for older adults-fear of injury are the main reasons for not behaving as planned [18] [20].

Social support (emotional, instrumental or informational support from others in specific life situations) is an important trigger of behavior change [8]. Having a network of people (mainly family, colleagues and friends) supporting the intention to engage in physical activity is especially helpful in initiating the intended behavior [21].

Self-efficacy (optimistic beliefs about one's capability to deal with barriers that arise during a period of physical activity) is one of the most important correlates of physical activity behavior [12] [13]. People with high levels of self-efficacy are significantly more active than those with lower levels. Reference [22] as well as [6] show that specific types of self-efficacy exist. Once an individual begins activity behavior, maintenance self-efficacy is crucial as individuals must cope with barriers like tiredness or stress.

Intrinsic motivation in the context of physical activity refers to being motivated to engage in exercise for its own sake, i.e. the motivation comes from the pleasure one gets from the task itself or from a sense of satisfaction in completing a task. There is evidence that intrinsically motivated people are better able to maintain physical activity over a long time in comparison to extrinsically motivated people [23] [24].

The feelings associated with physical activity behavior that stem from past experiences, e.g. sport at school, or information from others are expressed by affective attitudes [25]. Studies show that physical activity behavior can be significantly better predicted by affective rather than cognitive attitudes [25] [26]. Furthermore, interventions seem to be more effective in increasing self-reported level of physical activity using affective messages in comparison to cognitive messages [27].

\section{Objectives and Hypotheses of the Study}

While much research has focused on stage-based interventions in Western countries [18], little is known about the requirements for interventions to promote HEPA in East Asian countries [28]. Differences in requirements seem likely due to different cultural backgrounds, for example the collectivistic eastern tradition compared to the individualistic western tradition [29]. Thus, the present study examines the relationship of the psychosocial correlates of physical activity with the stages of change according to the FIT-model in an international sample of German and Chinese adults. The research questions are:

1) Can the hypothesized relationship between the selected psychosocial correlates and the stages of change be confirmed?

2) Is this relationship moderated by the participants’ national background?

Keeping consistent with the research and theory outlined above, it was hypothesized that:

1) Outcome expectations would play a major role in forming an intention to perform physical activity (not considering to considering, considering to preparing).

2) Barriers and social support would be especially important for initiating the intended behavior (preparing to exploring).

3) Maintenance self-efficacy and intrinsic motivation would be essential for performing physical activity regularly (preparing to exploring, fluctuating to maintaining).

4) Affective attitude would be important as well for forming an intention to perform physical activity as for performing physical activity regularly.

5) The relationship between the selected psychosocial correlates and the stages of change is moderated by the national background of the participants. 


\section{Methods}

\subsection{Participants and Data Collection}

Data was collected during a cooperative research project between the universities of Bayreuth (Germany) and Wuhan (China) between April and September 2010. In total, 2071 adults ( $n=865$ German, $n=1206$ Chinese) between the age of 27 and 55 years $(M=38.72, S D=8.67)$ formed the database for the analyses. There were 892 male and 1179 female persons in the sample, 726 persons had a lower and 1345 persons had a higher education (qualification for college/university was the distinction point). The study participants were mostly recruited from factories in Wuhan and Bayreuth. In addition, students from both universities gathered data from parents, relatives, and friends of the family. A power calculation was not done, but there should be a similar number of participants in each stage. All participants signed a letter of agreement that study participation was voluntary. The age range from the mid-twenties to the mid-fifties was selected, as during the "rush hour of life" HEPA is an important factor in the maintenance of physical and mental wellbeing and for preventing age-related diseases [2]. The anonymous questionnaires (online and print version) took 15 to 20 minutes to complete. Missing data was due to incomplete questionnaire answers and its deletion was pair wise.

\subsection{Measures}

The questionnaire was first developed and validated in the German language and subsequently translated into Chinese by the standard back-translation technique [30]. The validation process has been well documented elsewhere [31] [32]. The questionnaire packets contained assessments of the stages of change, maintenance self-efficacy, outcome expectations, barriers, social support, affective attitude, intrinsic motivation, and demographic variables.

Stages of physical activity behavior change

The stages of change in physical activity behavior were measured using a specially developed construct to reflect the definition of stages of the FIT-Model. A scale of six categories was used and these were labelled according to the recommendations for an acceptable stage algorithm [33]. Participants were asked to think of all physical activity, including activities at work, activities for the purpose of traveling to and from places and activities during leisure time (sport, fitness or homework), which are performed at least a moderate intensity. Participants were then asked to indicate their agreement to a choice of statements. For example, not considering: $I$ perform physical activity less than 150 minutes per week and I am not thinking about doing any more in the future.

The stage algorithm was validated by an established self-reported physical activity measure [34]. The distribution of the average weekly energy consumption per stage showed that energy consumption in the inactive stages—not considering ( $222 \mathrm{kcal} / \mathrm{wk})$, considering ( $257 \mathrm{kcal} / \mathrm{wk}$ ), and preparing (479 kcal/wk)—was below the lowest acceptable level of HEPA (800 kcal/wk), whereas energy consumption in the active stages-exploring (1620 kcal/wk), maintaining (2048 kcal/wk) and fluctuating (1197 kc/wk)—was above this level [7].

Outcome expectations

An 18-item instrument [15] measured participants' expected outcomes from performing physical activity. Participants rated items on a 7-point-scale (not true at all to exactly true) the benefit they expected from performing physical activity regularly (e.g. to improve my fitness or to meet friends). The internal consistencies of the German and Chinese versions of the measure were 0.87 and 0.92 , respectively.

Barriers

Barriers regarding physical activity were determined by asking participants to assess 15 possible reasons that would deter them from engaging in physical activity (e.g. having no time or lack of motivation) [35] on a 7-point-scale (not agree at all to definitely agree). The internal consistencies of the German and Chinese versions of the measure were 0.88 and 0.92 , respectively.

Social support

Social support for physical activity was measured using a 6-item-scale, reporting the support from family, friends, acquaintances and co-workers [36]. Participants rated items on a 5-point-scale (never to very often) as to how often these groups are supportive to them being physically active (e.g. encourage me to perform physical activity). The internal consistencies of the German and Chinese versions of the measure were 0.78 and 0.79 , respectively. 


\section{Maintenance self-efficacy}

Maintenance self-efficacy for physical activity was assessed using a 5-item measure [6]. Participants indicated on a 5-point-scale (not confident at all to extremely confident) to what extent they were confident in their ability to perform physical activity in the face of potential barriers (e.g. being tired or having a lot of work to do). The internal consistencies of the German and Chinese versions of the measure were 0.86 and 0.80 , respectively.

Intrinsic motivation

The degree of intrinsic motivation was measured using three items from the self-concordance scale [37] which is based on the self-determination theory [24]. On a 6-point-scale (not true at all to extremely true) participants rated items according to the extent intrinsic reasons motivate them to engage in physical activity (e.g. because it's fun). The internal consistencies of the German and Chinese versions of the measure were 0.76 and 0.82 , respectively.

Affective attitude

Four items assessed affective attitudes towards physical activity [25]. For each item participants had to report how they feel when considering physical activity (e.g. unpleasant-pleasant). Participants responded using 7point scales with 1 and 7 anchored at each end of the semantic differential. The internal consistencies of the German and Chinese versions of the measure were 0.86 and 0.93 , respectively.

Statistical analysis

Stages of change were coded from 1 (not considering) to 6 (maintaining). The fluctuation stage was situated between exploring and maintaining (coded as " 5 "). Descriptive analyses were used to describe the distribution of study participants across the stages of change. In the next step, a two-way ANOVA with post-hoc comparison (Tukey) was conducted to test the relationship between psychosocial correlates, stages of change and the nationality of the study participants. The significant differences between some, but not all adjacent stages, were interpreted according to stage-specific importance regarding these correlates [38]. A further purpose was to understand, whether there was an interaction between the stages of change and nationality on the psychosocial correlates. Significant interactions between the stages and nationality served as an indication for the varying importance of certain correlates related to the behavior change process for German and Chinese people. All analyses were calculated using SPSS 21.0.

\section{Results}

Table 1 demonstrates the distribution of participants across the stages of change. In Germany, almost half of the participants assigned themselves into the maintaining stage. In China, a more balanced distribution across the stages of change was found.

Table 2 shows the relationship between psychosocial correlates and the stages of change. Mean values increased for all correlates across the stages of change, and decreased for barriers. There were significant main effects of the stages of change on all psychosocial correlates with small (outcome expectations) and large (barriers, social support, maintenance self-efficacy, intrinsic motivation and affective attitudes) effect sizes [39]. Post-hoc tests between adjacent stages revealed only one significant difference in mean values for outcome expectations between not considering and considering. For barriers, significant differences appeared between not considering and considering, preparing and exploring as well as fluctuating and maintaining. For social support, the pattern was different. Significant differences were found between not considering and considering, considering and

Table 1. Stage distribution of participants $(\mathrm{N}=2071)$.

\begin{tabular}{|c|c|c|c|}
\hline Stage & Germany & China & Total \\
\hline Not considering & $70(8.1 \%)$ & 147 (12.2\%) & 217 (10.5\%) \\
\hline Considering & 97 (11.2\%) & 273 (22.6\%) & 370 (17.9\%) \\
\hline Preparing & $66(7.6 \%)$ & 148 (12.3\%) & $214(10.3 \%)$ \\
\hline Exploring & $71(8.2 \%)$ & 144 (11.9\%) & 215 (10.4\%) \\
\hline Fluctuating & 164 (19.0\%) & 201 (16.7\%) & 365 (17.6\%) \\
\hline Maintaining & 397 (45.9\%) & $293(24.3 \%)$ & $690(33.3 \%)$ \\
\hline Total & 865 (41.8\%) & 1206 (58.2\%) & 2071(100\%) \\
\hline
\end{tabular}


Table 2. Descriptive statistics of psychosocial correlates across stages and results from group comparisons $(\mathrm{n}=1493-2071)^{\#}$.

\begin{tabular}{|c|c|c|c|c|c|c|c|}
\hline \multirow{2}{*}{$\begin{array}{c}\text { Physical activity } \\
\text { stage } \\
\text { Psychosocial } \\
\text { Correlates (n) }\end{array}$} & $\begin{array}{c}\text { Not } \\
\text { Considering } \\
\left(\mathrm{n}_{\max }=218\right)\end{array}$ & $\begin{array}{l}\text { Considering } \\
\left(\mathrm{n}_{\max }=370\right)\end{array}$ & $\begin{array}{c}\text { Preparing } \\
\left(\mathrm{n}_{\max }=214\right)\end{array}$ & $\begin{array}{c}\text { Exploring } \\
\left(\mathrm{n}_{\max }=215\right)\end{array}$ & $\begin{array}{l}\text { Fluctuating } \\
\left(\mathrm{n}_{\max }=365\right)\end{array}$ & $\begin{array}{l}\text { Maintaining } \\
\left(\mathrm{n}_{\max }=690\right)\end{array}$ & \\
\hline & $\begin{array}{c}\text { Mean } \\
\text { (Standard } \\
\text { Deviation) }\end{array}$ & $\begin{array}{c}\text { Mean } \\
\text { (Standard } \\
\text { Deviation) }\end{array}$ & $\begin{array}{c}\text { Mean } \\
\text { (Standard } \\
\text { Deviation) }\end{array}$ & $\begin{array}{c}\text { Mean } \\
\text { (Standard } \\
\text { Deviation) }\end{array}$ & $\begin{array}{c}\text { Mean } \\
\text { (Standard } \\
\text { Deviation) }\end{array}$ & $\begin{array}{c}\text { Mean } \\
\text { (Standard } \\
\text { Deviation) }\end{array}$ & \\
\hline Outcome expectations & $4.29^{\mathrm{a}}(1.19)$ & $4.61^{\mathrm{b}}(1.13)$ & $4.82^{\mathrm{b}}(1.17)$ & $4.77^{\mathrm{b}}(1.06)$ & $4.86^{\mathrm{b}}(1.10)$ & $4.97^{\mathrm{b}}(1.08)$ & $\begin{array}{c}\mathrm{F}_{5,2069}=17.62^{*} \\
\eta^{2}=0.041\end{array}$ \\
\hline Barriers & $3.70^{\mathrm{a}}(1.12)$ & $3.43^{\mathrm{b}}(0.89)$ & $3.31^{\mathrm{b}}(1.01)$ & $2.44^{\mathrm{c}}(0.85)$ & $2.60^{\mathrm{c}}(0.82)$ & $1.97^{\mathrm{d}}(0.81)$ & $\begin{aligned} \mathrm{F}_{5,2069} & =212.51^{*} \\
\eta^{2} & =0.341\end{aligned}$ \\
\hline Social support & $2.21^{\mathrm{a}}(0.81)$ & $2.47^{\mathrm{b}}(0.74)$ & $2.76^{\mathrm{c}}(0.74)$ & $2.93^{\mathrm{c}}(0.79)$ & $2.88^{\mathrm{c}}(0.76)$ & $3.06^{\mathrm{d}}(0.84)$ & $\begin{array}{c}\mathrm{F}_{5,2071}=71.36^{*} \\
\eta^{2}=0.147\end{array}$ \\
\hline $\begin{array}{l}\text { Maintenance } \\
\text { self-efficacy }\end{array}$ & $2.33^{\mathrm{a}}(0.80)$ & $2.45^{\mathrm{a}}(0.71)$ & $2.63^{\mathrm{a}}(0.77)$ & $2.96^{\mathrm{b}}(0.75)$ & $2.90^{\mathrm{b}}(0.73)$ & $3.37^{\mathrm{c}}(0.84)$ & $\begin{array}{c}\mathrm{F}_{5,2071}=90.60^{*} \\
\eta^{2}=0.180\end{array}$ \\
\hline Intrinsic motivation & - & - & $3.96^{\mathrm{a}}(1.04)$ & $4.28^{\mathrm{b}}(0.95)$ & $4.21^{\mathrm{b}}(0.96)$ & $4.91^{\mathrm{c}}(0.91)$ & $\begin{array}{c}\mathrm{F}_{3,1493}=87.32 * \\
\eta^{2}=0.150\end{array}$ \\
\hline Affective attitude & $4.08^{\mathrm{a}}(1.48)$ & $4.56^{\mathrm{b}}(1.39)$ & $4.93^{\mathrm{c}}(1.39)$ & $5.43^{\mathrm{d}}(1.24)$ & $5.30^{\mathrm{d}}(1.22)$ & $5.72^{\mathrm{e}}(1.23)$ & $\begin{array}{c}\mathrm{F}_{5,2071}=72.22^{*} \\
\eta^{2}=0.149\end{array}$ \\
\hline
\end{tabular}

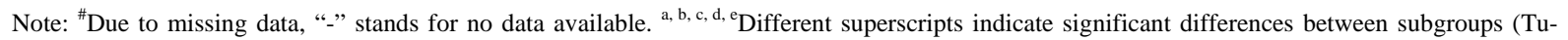
key-test). ${ }^{*} \mathrm{p}<0.001$.

preparing as well as fluctuating and maintaining. For maintenance self-efficacy and intrinsic motivation, mean values differed significantly between preparing and exploring as well as between fluctuating and maintaining. In terms of affective attitudes, only mean values between the exploring and fluctuating stages did not differ significantly.

Table 3 shows the nation-specific means of the psychosocial correlates across the stages of change. Significant interactions of nationality and stages of change appeared for all correlates, although the results only revealed small effect sizes. Considering outcome expectations, nation-specific differences appeared for the stages of activity. Although the mean values decreased between exploring and fluctuating and increased between fluctuating and maintaining in the German sample, the opposite was found in the Chinese sample. In terms of barriers, larger decreases in mean values between preparing and exploring as well as between fluctuating and maintaining were found for Germans in comparison to the Chinese sample. Regarding social support, increasing mean values were detected between exploring and fluctuating for Germans. On the contrary, mean values decreased for the Chinese sample between these stages. Considering maintenance self-efficacy, mean values increased by a larger amount in the German sample between preparing and exploring as well as between fluctuating and maintaining compared to the Chinese sample. Concerning intrinsic motivation in the Chinese sample, the mean value trend was similar between preparing, exploring and fluctuating and increased between fluctuating and maintaining. In the German sample, mostly increasing mean values were found between preparing and exploring as well as between fluctuating and maintaining. For affective attitudes, larger increases in mean values appeared for Germans between preparing and exploring as well as fluctuating and maintaining than for the Chinese sample.

\section{Discussion}

This study investigated the relationship of fundamental psychosocial correlates of behaviour change (maintenance self-efficacy, barriers, outcome expectations, social support, affective attitudes and intrinsic motivation) with the stages of change in a German-Chinese sample. Of special interest was the moderating influence of nationality on the association of the correlates of physical activity with the stages of change. In the following section, the results of the study are discussed in detail concerning the hypotheses and their relevance to intervention planning.

In support of hypothesis 1 (outcome expectations would play a major role in forming an intention to become more active), significant differences in the mean values of outcome expectations appeared between not considering and considering. However, no significant differences were found between the stages considering and preparing. This would have been supposed by reflecting results from literature [14] [17]. Therefore, the current 
Table 3. Nation-specific descriptive statistics for psychosocial correlates across stages and interaction terms (stage* nationality).

\begin{tabular}{|c|c|c|c|c|c|c|c|}
\hline \multirow{3}{*}{$\begin{array}{l}\text { Physical } \\
\text { activity stage } \\
\text { Psychosocial } \\
\text { Correlates }\end{array}$} & $\begin{array}{l}\text { Not } \\
\text { Considering } \\
\left(\mathrm{n}_{\operatorname{maxG}}=70\right)\end{array}$ & $\begin{array}{l}\text { Considering } \\
\left(\mathrm{n}_{\operatorname{maxG}}=97\right)\end{array}$ & $\begin{array}{l}\text { Preparing } \\
\left(\mathrm{n}_{\operatorname{maxG}}=66\right)\end{array}$ & $\begin{array}{l}\text { Exploring } \\
\left(\mathrm{n}_{\operatorname{maxG}}=71\right)\end{array}$ & $\begin{array}{l}\text { Fluctuating } \\
\left(\mathrm{n}_{\operatorname{maxG}}=164\right)\end{array}$ & $\begin{array}{l}\text { Maintaining } \\
\left(\mathrm{n}_{\operatorname{maxG}}=397\right)\end{array}$ & \multirow{3}{*}{$\begin{array}{l}\text { Interaction } \\
\text { stage* }^{*} \\
\text { nationality }\end{array}$} \\
\hline & $\left(\mathrm{n}_{\operatorname{maxC}}=147\right)$ & $\left(\mathrm{n}_{\operatorname{maxC}}=273\right)$ & $\left(\mathrm{n}_{\operatorname{maxC}}=148\right)$ & $\left(\mathrm{n}_{\operatorname{maxC}}=144\right)$ & $\left(\mathrm{n}_{\operatorname{maxC}}=201\right)$ & $\left(\mathrm{n}_{\operatorname{maxC}}=293\right)$ & \\
\hline & $\begin{array}{l}\text { Mean } \\
\text { (Standard } \\
\text { Deviation) }\end{array}$ & $\begin{array}{l}\text { Mean } \\
\text { (Standard } \\
\text { Deviation) }\end{array}$ & $\begin{array}{l}\text { Mean } \\
\text { (Standard } \\
\text { Deviation) }\end{array}$ & $\begin{array}{l}\text { Mean } \\
\text { (Standard } \\
\text { Deviation) }\end{array}$ & $\begin{array}{l}\text { Mean } \\
\text { (Standard } \\
\text { Deviation) }\end{array}$ & $\begin{array}{l}\text { Mean } \\
\text { (Standard } \\
\text { Deviation) }\end{array}$ & \\
\hline $\begin{array}{l}\text { Outcome } \\
\text { expectations }_{\mathrm{Ger}}\end{array}$ & $3.97(0.84)$ & $4.42(0.86)$ & $4.57(0.77)$ & $4.60(0.92)$ & $4.57(0.83)$ & 4.94 (0.93) & \multirow{2}{*}{$\begin{array}{l}\mathrm{F}_{5,2069}=2.53 \\
\mathrm{p}<0.05 \\
\eta^{2}=0.01\end{array}$} \\
\hline $\begin{array}{l}\text { Outcome } \\
\text { expectations } \\
\text { China }\end{array}$ & $4.45(1.30)$ & $4.67(1.21)$ & 4.93 (1.29) & 4.85 (1.11) & $5.10(1.14)$ & $5.02(1.27)$ & \\
\hline Barriers $_{\mathrm{Ger}}$ & 3.92 (1.00) & $3.64(0.77)$ & $3.44(0.64)$ & $2.35(0.78)$ & $2.65(0.75)$ & $1.86(0.69)$ & \multirow{2}{*}{$\begin{array}{l}\mathrm{F}_{5,2069}=6.44 \\
\mathrm{p}<0.001 \\
\eta^{2}=0.02\end{array}$} \\
\hline Barriers $_{\text {China }}$ & $3.60(1.16)$ & $3.36(0.92)$ & $3.26(1.13)$ & $2.48(0.87)$ & $2.57(0.88)$ & $2.13(0.92)$ & \\
\hline Social support $_{G e r}$ & $1.63(0.77)$ & $1.97(0.72)$ & $2.41(0.99)$ & $2.53(0.98)$ & $2.74(1.06)$ & 3.01 (1.11) & \multirow{2}{*}{$\begin{array}{l}\mathrm{F}_{5,2071}=2.22 \\
\mathrm{p}=0.050 \\
\eta^{2}=0.01\end{array}$} \\
\hline $\begin{array}{l}\text { Social } \\
\text { support }_{\text {China }}\end{array}$ & $2.37(0.84)$ & $2.56(0.83)$ & $2.92(0.88)$ & $3.15(0.86)$ & $2.98(0.84)$ & $3.33(0.85)$ & \\
\hline $\begin{array}{l}\text { Maintenance } \\
\text { self-efficacy } \\
G e r\end{array}$ & $2.39(0.79)$ & $2.41(0.75)$ & $2.74(0.83)$ & $3.33(0.66)$ & 3.15 (0.69) & $3.64(0.77)$ & \multirow{2}{*}{$\begin{array}{l}\mathrm{F}_{5,2071}=12.01, \\
\mathrm{p}<0.001, \\
\eta^{2}=0.03\end{array}$} \\
\hline $\begin{array}{l}\text { Maintenance } \\
\text { self-efficacy }\end{array}$ & $2.30(0.81)$ & $2.47(0.70)$ & $2.58(0.74)$ & $2.77(0.73)$ & $2.70(0.70)$ & $3.00(0.70)$ & \\
\hline $\begin{array}{l}\text { Intrinsic } \\
\text { motivation }_{\mathrm{Ger}}\end{array}$ & - & - & 3.42 (1.06) & $4.29(1.05)$ & $4.06(1.01)$ & 5.05 (0.83) & \multirow{2}{*}{$\begin{array}{l}\mathrm{F}_{3,1493}=20.38, \\
\mathrm{p}<0.001, \\
\eta^{2}=0.04\end{array}$} \\
\hline $\begin{array}{l}\text { Intrinsic } \\
\text { motivation }_{\text {China }}\end{array}$ & - & - & $4.20(0.94)$ & $4.27(0.91)$ & $4.33(0.91)$ & $4.71(0.97)$ & \\
\hline $\begin{array}{l}\text { Affective } \\
\text { attitude }_{\mathrm{Ger}}\end{array}$ & $3.84(1.46)$ & $4.27(1.28)$ & $4.80(1.33)$ & $5.60(0.94)$ & $5.30(1.15)$ & $5.86(0.95)$ & \multirow{2}{*}{$\begin{array}{l}\mathrm{F}_{5,2071}=4.70 \\
\mathrm{p}<0.001 \\
\eta^{2}=0.01\end{array}$} \\
\hline $\begin{array}{l}\text { Affective } \\
\text { attitude }_{\text {China }}\end{array}$ & $4.18(1.48)$ & $4.67(1.42)$ & 4.99 (1.42) & $5.34(1.36)$ & $5.31(1.28)$ & $5.52(1.52)$ & \\
\hline
\end{tabular}

Note: “-” stands for no data available. G = Germany, C = China.

study results suggest that informational (media) campaigns could be an important method to promote health behavior change by increasing awareness, but may not necessarily foster a strong decision to perform physical activity.

In response to hypothesis 2 (barriers and social support would be especially important for initiating the intended behavior) barriers differed significantly between preparing and exploring whereas social support did not. According to the literature [18] [20], the results of the current study demonstrate the difficulty involved when implementing intended behaviors in the face of barriers. However, social support seems to be less important for initiating physical activity behavior which is inconsistent with previous studies [7] [21] [40]. Instead, social support plays a major role during the stages of inactivity in the current study. Therefore, HEPA promotion interventions should focus on creating social networks for inactive people, helping them to form a concrete intention to begin to engage in physical activity. Social support also seems to be of particular importance in maintaining physical activity behavior, thus people should be encouraged to look for companionship in order to engage in regular physical activity. Furthermore, the current study results show that the subjective perception of barriers is not only relevant for implementing the intended behavior but also for progressing from not considering to considering and for performing physical activity regularly. As a consequence, the specific reasons that inactive people have against physical activity should be identified and addressed in interventions in order to reduce the perception of barriers. Additionally, those performing irregular physical activity could be supported by brief interventions related to creating adequate volitional coping strategies [41].

The results of the study support hypothesis 3 in that maintenance self-efficacy and intrinsic motivation are 
essential for performing regular physical activity. Significant mean value differences for both correlates were found between the stages preparing and exploring as well as between fluctuating and maintaining. Therefore, for regular physical activity behavior, people must be shown how they can cope with obstacles like tiredness or stress both at work and at home [6] [22]. Additionally, HEPA promotion interventions should focus on the enjoyment of physical activity, as intrinsically motivated people are better able to maintain physical activity over a long period of time [23] [24].

Supporting hypothesis 4 this study has contributed to existing research that emphasizes the importance of positive feelings towards physical activity behavior for effective health behavior change [25] [26]. Significant differences appeared between all stages of change expect between exploring and fluctuating. As a consequence, HEPA interventions should emphasize the exploration of the positive emotional effects of performing physical activity for people in the stages of inactivity and activity.

Finally, according to hypothesis 5 (the relationship of the correlates with stages of change is moderated by the national background of the study participants) the results show significant interactions between the stages of change and nationality for all correlates. However, the small effect sizes indicate that there are only few implications for nation-specific interventions. Obviously, differences between individualist and collectivistic cultures have limited influence on physical activity behavior change. However, several characteristics were found and their consequences for HEPA interventions are summarized below.

As the mean value of outcome expectations increased between fluctuating and maintaining, Germans in the fluctuating stage could benefit from strengthening their outcome expectations. Chinese probably would not, as the highest level of outcome expectations is already reported on the fluctuating stage. Furthermore, for performing physical activity regularly, especially Germans should be empowered to cope with barriers like tiredness or stress. This suggestion is due to larger decreases in the mean barrier values between the stages preparing and exploring as well as between fluctuating and maintaining for Germans compared to the Chinese. The same pattern is found for maintenance self-efficacy which supports the previously proposed consequence, as higher self-efficacy expectations result in lower perceptions of barriers and the same is true for the reverse of this finding. Regarding social support, Germans at the active stages may not necessarily benefit from encouragement or instrumental help from others (higher mean values at the fluctuating stage compared to the exploring stage). The opposite is true for the Chinese adults, as the mean values decreased between exploring and fluctuating and increased between fluctuating and maintaining. The emotional aspects of regular physical activity behavior should be given particular attention in HEPA interventions for German people, as the mean increases between preparing and exploring as well as between fluctuating and maintaining for affective attitude and intrinsic motivation are much higher compared to the Chinese sample.

\section{Conclusion and Limitations}

Interventions to promote HEPA should be tailored to the specific needs of the target group. The current study results show that at different stages in the behavior change process different psychosocial correlates have to be addressed in order to progress to the next stage. Considering the comparison between the two nationalities, there are only a few implications for nation-specific interventions. There are major limitations to the present study. First, the cross-sectional design did not provide the strongest evidence for causal relationships. Thus, future longitudinal and interventions studies need to be conducted to investigate the different roles of psychosocial correlates on different stages of change. Second, the reliance on the participants' self-report of physical activity may be another limitation. The measure of physical activity behavior employed in this study is well validated; however, it would be desirable to examine physical activity behavior objectively for an improved validation of the stage assessment.

\section{References}

[1] Bouchard, C., Blair, S.N. and Haskell, W.L. (2007) Physical Activity and Health. Human Kinetics, Champaign.

[2] WHO (2010) Global Recommendations on Physical Activity for Health. World Health Organization, Geneva.

[3] Krug, S., Jordan, S. and Lampert, T. (2012) Physical Activity: What Are the Patterns among Germans? Bundesgesundheitsblatt, 1, 6-7.

[4] Chen, X.R., Jiang, Y., Wang, L.M., Li, Y.C., Zhang, M., et al. (2012). Leisure-Time Physical Activity and Sedentary Behaviors among Chinese Adults in 2010. Chinese Journal of Preventive Medicine, 46, 399-403. 
[5] Prochaska, J.O., DiClemente, C.C. and Norcross, J.C. (1992) In Search of How People Change: Applications to Addictive Behaviours. American Psychologist, 47, 1102-1114. http://dx.doi.org/10.1037/0003-066X.47.9.1102

[6] Schwarzer, R. (2008) Modelling Health Behaviour Change: How to Predict and Modify the Adoption and Maintenance of Health Behaviours. Applied Psychology, 57, 1-29.

[7] Duan, Y.P., Brehm, W., Strobl, H., Tittlbach, S., Huang, Z.J. and Si, G.Y. (2013) Steps to and Correlates of Health Enhancing Physical Activity in Adulthood. Journal of Exercise Science and Fitness, 11, 63-77. http://dx.doi.org/10.1016/j.jesf.2013.07.001

[8] Biddle, S.J.H., Brehm, W., Verheijden, M.V. and Hopman-Rock, M. (2012) Population Physical Activity Behaviour Change: A Review for the European College of Sport Science. European Journal of Sport Science, 12, 367-383. http://dx.doi.org/10.1080/17461391.2011.635700

[9] Lippke, S., Ziegelmann, J.P. and Schwarzer, R. (2005) Stage-specific Adoption and Maintenance of Physical Activity: Testing a Three-Stage Model. Psychology of Sport and Exercise, 6, 585-603. http://dx.doi.org/10.1016/j.psychsport.2004.11.002

[10] Fuchs, R. (2001) Entwicklungsstadien des Sporttreibens [Evolutional States of Physical Activity Behaviour]. Sportwissenschaft, 31, 255-281.

[11] Brehm, W., Wagner, P., Sygusch, R., Hahn, U. and Janke, A. (2005) Health Promotion by Means of Health Sport. A Framework and a Controlled Intervention Study with Sedentary Adults. Scandinavian Journal of Medicine and Science in Sports, 15, 13-20. http://dx.doi.org/10.1111/j.1600-0838.2003.00369.x

[12] Sallis, J.F. and Owen, N. (2003) Physical Activity and Behavioral Medicine. Sage Publications, Thousand Oaks.

[13] Trost, S.G., Owen, N., Bauman, A.E., Sallis, J.F. and Brown, W. (2002) Correlates of Adult’s Participation in Physical Activity: Review and Update. Medicine and Science in Sports and Exercise, 34, 1996-2001. http://dx.doi.org/10.1097/00005768-200212000-00020

[14] Rhodes, R.E. and Pfaeffli, L.A. (2010) Mediators of Physical Activity Behaviour Change among Adult Non-Clinical Populations: A Review Update. International Journal of Behavioral Nutrition and Physical Activity, 7, 37. http://dx.doi.org/10.1186/1479-5868-7-37

[15] Brehm, W. and Pahmeier, I. (2006) Kompetenz- und Konsequenzerwartungen [Competence and Outcome Expectations]. In: Bös, K. and Brehm, W., Eds., Handbuch Gesundheitssport, Hofmann, Schorndorf, 346-356.

[16] Williams, D.M., Anderson, E.S. and Winett, R.A. (2005) A Review of the Outcome Expectancy Construct in Physical Activity Research. Annals of Behavioural Medicine, 29, 70-79. http://dx.doi.org/10.1207/s15324796abm2901_10

[17] Ajzen, I. (1991) The Theory of Planned Behavior. Organizational Behavior and Human Decision Processes, 50, 179211. http://dx.doi.org/10.1016/0749-5978(91)90020-T

[18] Biddle, S.J.H. and Mutrie, N. (2008) Psychology of Physical Activity. Routledge, London.

[19] Sheeran, P. (2002) Intention-Behavior Relations: A Conceptual and Empirical Review. European Review of Social Psychology, 12, 1-36. http://dx.doi.org/10.1080/14792772143000003

[20] de Bourdeaudhuij, I. and Sallis, J. (2002) Relative Contribution of Psychosocial Variables to the Explanation of Physical Activity in Three Population-Based Adult Samples. Preventive Medicine, 34, 279-288. http://dx.doi.org/10.1006/pmed.2001.0979

[21] Sallis, J.F., Hovell, M.F., Hofstetter, C.R. and Barrington, E. (1992) Explanation of Vigorous Physical Activity during Two Years Using Social Learning Variables. Social Science and Medicine, 34, 5-32. http://dx.doi.org/10.1016/0277-9536(92)90063-V

[22] Rodgers, W.M., Hall, C.R., Blanchard, C.M., McAuley, E. and Munroe, K.J. (2002) Task and Scheduling Self-Efficacy as Predictors of Exercise Behaviour. Psychology and Health, 17, 405-416. http://dx.doi.org/10.1080/0887044022000004902

[23] Teixera, P.J., Going, S.B., Houtkooper, L.B., Cussler, E.C., Metcalfe, L.L., et al. (2006) Exercise Motivation, Eating, and Body Image Variables as Predictor of Weight Control. Medicine and Science in Sports and Exercise, 38, 179-188. http://dx.doi.org/10.1249/01.mss.0000180906.10445.8d

[24] Ryan, R.M. and Deci, E.L. (2000) Self-Determination Theory and the Facilitation of Intrinsic Motivation, Social Development, and Well-Being. American Psychologist, 55, 68-79. http://dx.doi.org/10.1037/0003-066X.55.1.68

[25] Kiviniemi, M.T., Voss-Humke, A.M. and Seifert, A.L. (2007) How Do I Feel about the Behaviour? The Interplay of Affective Associations with Behaviours and Cognitive Beliefs as Influence on Physical Activity Behaviour. Health Psychology, 26, 152-158. http://dx.doi.org/10.1037/0278-6133.26.2.152

[26] Eagly, A. and Chaiken, S. (1993) The Psychology of Attitudes. Harcourt Brac, Fort Worth.

[27] Conner, M., Rhodes, R.E., Morris, B., McEachan, R. and Lawton, R. (2011) Changing Exercise through Targeting Affective or Cognitive Attitudes. Psychology and Health, 26, 133-149. http://dx.doi.org/10.1080/08870446.2011.531570 
[28] Duan, Y. (2006) Stage Models of Physical Activity Behaviour and Their Application to Chinese Adults. Dissertation, University Bayreuth, Bayreuth.

[29] Triandis, H.C. (2001) Individualism-Collectivism and Personality. Journal of Personality, 69, 907-924. http://dx.doi.org/10.1111/1467-6494.696169

[30] van de Vijver, F. and Hambleton, R.K. (1996) Translating Tests: Some Practical Guidelines. European Psychologist, 1, 89-99. http://dx.doi.org/10.1027/1016-9040.1.2.89

[31] Brehm, W., Duan, Y., Mair, T., Strobl, H. and Tittlbach, S. (2010) Körperlich-sportliche Aktivität als Gesundheitsverhalten. Das FIT-Stufen-Modell [Physical Activity as Health Behaviour. The FIT-Stage-Model]. Bayreuther Beiträge zur Sportwissenschaft, 12, University Bayreuth, Bayreuth.

[32] Duan, Y.P., Huang, Z., Si, G., Wei, X. and Brehm, W. (2010) Physical Activity as Health Behavior. The FIT-StageModel. Bayreuther Beiträge zur Sportwissenschaft, 13, University Bayreuth, Bayreuth. (In Chinese)

[33] Reed, G.R., Velicer, W.F., Prochaska, J.O., Rossi, J.S. and Marcus, B.H. (1997) What Makes a Good Staging Algorithm: Examples from Regular Exercise. American Journal of Health Promotion, 12, 57-66. http://dx.doi.org/10.4278/0890-1171-12.1.57

[34] Woll, A. (1996) Gesundheitsförderung in der Gemeinde-Eineempirische Untersuchungzum Zusammenhang von sportlicher Aktivität, Fitness und Gesundheitbei Personenimmittleren und späten Erwachsenenalter [Health Promotion in the Community-An Empirical Investigation of the Relationship between Physical Activity, Fitness and Health in Middle-Aged and Older Adults]. LinguaMed, NeuIsenburg.

[35] Brehm, W. and Eberhardt, J. (1995) Drop-out und BindungimFitneß-Studio [Drop-Out and Adherence to Fitness Centers]. Sportwissenschaft, 25, 174-186.

[36] Sallis, J.F., Grossman, R.M., Pinski, R.B., Patterson, T.L. and Nader, P.R. (1987) The Development of Scales to Measure Social Support for Diet and Exercise Behaviors. Preventive Medicine, 16, 825-836. http://dx.doi.org/10.1016/0091-7435(87)90022-3

[37] Seelig, H. and Fuchs, R. (2006) Messung der sport- und bewegungsbezogenen Selbstkonkordanz [Measurement of Intrinsic Motivation in Sport and Physical Activity]. Zeitschrift für Sportpsychologie, 13, 121-139. http://dx.doi.org/10.1026/1612-5010.13.4.121

[38] Sutton, S. (2000) Interpreting Cross-Sectional Data on Stages of Change. Psychology and Health, 15, 163-171. http://dx.doi.org/10.1080/08870440008400298

[39] Cohen, J. (1988) Statistical Power Analysis for the Behavioural Sciences. 2nd Edition, Erlbaum, Hillsdale.

[40] Lippke, S. and Plotnikoff, R.C. (2006) Stages of Change in Physical Exercise: A Test of Stage Discrimination and Non-Linearity. American Journal of Health Behavior, 30, 290-301. http://dx.doi.org/10.5993/AJHB.30.3.7

[41] Sniehotta, F.F., Scholz, U. and Schwarzer, R. (2006) Action Plans and Coping Plans for Physical Exercise: A Longitudinal Intervention Study in Cardiac Rehabilitation. British Journal of Health Psychology, 11, 23-37. http://dx.doi.org/10.1348/135910705X43804 